\title{
Ver, ouvir e a atitude fenomenológica
}

\author{
See, hear and the phenomenological attitude \\ Ver, oír y la actitud fenomenológica
}

Recebido: 22/03/2021 | Revisado: 20/03/2021 | Aceito: 01/04/2021 | Publicado: 06/04/2021

\author{
Cezar Luís Seibt \\ ORCID: https://orcid.org/0000-0003-0166-0919 \\ Universidade Federal do Pará, Brasil \\ E-mail: celuse@ufpa.br \\ Adelma do Socorro Gonçalves Pimentel \\ ORCID: https://orcid.org/0000-0003-0048-4976 \\ Universidade Federal do Pará, Brasil \\ E-mail: pimenteladelma@gmail.com \\ Maria de Nazareth Rodrigues Malcher de Oliveira Silva \\ ORCID: https://orcid.org/0000-0003-4405-7378 \\ Faculdade Ceilândia, Brasil \\ Universidade de Brasília, Brasil \\ E-mail: malchersilva@unb.br
}

\begin{abstract}
Resumo
Este artigo é uma reflexão sobre nossa condição compreensiva no mundo, enfocando dois modos possíveis de entender, se relacionar e agir no mundo, com base nas metáforas do ver e ouvir. $\mathrm{O}$ ver associado com a atividade, com o controle, posse, fragmentação e domínio sobre as coisas. O ouvir, por outro lado, caracteriza a atitude receptiva, acolhedora, integradora, que deixa-ser. Mostramos que na tradição ocidental há primazia da visão em relação à escuta, de forma que nos esforçamos gradativamente para colocar a realidade dentro dos limites de nossos projetos e representações, ou seja, objetificamos o mundo, as coisas e nós mesmos. Aquilo que conhecemos como fenomenologia no século XX é uma consciência da possibilidade de voltarmos para a experiência viva e integrada das coisas. Não se trata de um apelo para a negação e supressão da nossa atitude predominante, mas o desenvolvimento de uma disposição para deixar as coisas elas mesmas pronunciarem sua palavra, de forma a propiciar um diálogo entre as aquisiçõos culturais historicamente disponíveis e o que se oferece aqui e agora, na sua ocasionalidade e no fluxo e interconexão da vida no mundo. Um diálogo entre as representações e as próprias coisas; entre o ver e ouvir.
\end{abstract}

Palavras-chave: Fenomenologia; Ver; Ouvir; Diálogo.

\begin{abstract}
This article consists of a bibliographic research and a reflection about our understanding condition in the world, focusing on two possible ways of understanding, relating and acting in the world, based on the metaphors of seeing and hearing. Seeing is associated with activity, with control, possession, fragmentation and dominion over things. Listening, on the other hand, characterizes more the receptive, welcoming, integrating attitude, which allows to be. We show that in the western tradition there is the primacy of vision over listening, so that we gradually strive to place reality within the limits of our projects and representations, that is, we objectify the world, things and ourselves. What we know as phenomenology in the 20th century is an awareness of the possibility of going back to the living and integrated experience of things. This is not a call for the denial and suppression of our prevailing attitude, but for the development of a willingness to let things say their own words, in order to provide a dialogue between the cultural acquisitions historically available and what is offered here and now, in its occasionality and in the flow and interconnection of life in the world. A dialogue between representations and things themselves; between seeing and hearing.
\end{abstract}

Keywords: Phenomenology; Seeing; Hearing; Dialogue.

\section{Resumen}

Este artículo consiste en una investigación bibliográfica y una reflexión sobre nuestra condición de comprensión en el mundo, centrándose en dos posibles formas de entender, relacionarse y actuar en el mundo, a partir de las metáforas del ver y el oír. Ver está asociado con la actividad, con el control, la posesión, la fragmentación y el dominio sobre las cosas. Escuchar, en cambio, caracteriza más la actitud receptiva, acogedora, integradora, que deja ser. Demostramos que en la tradición occidental hay primacía de la visión sobre la escucha, por lo que poco a poco nos esforzamos por situar la realidad dentro de los límites de nuestros proyectos y representaciones, es decir, objetivamos el mundo, las cosas y nosotros mismos. Lo que conocemos como fenomenología en el siglo XX es una conciencia de la posibilidad de volver a la experiencia viva e integrada de las cosas. No se trata de un llamado a la negación y represión de nuestra actitud imperante, sino al desarrollo de la voluntad de dejar que las cosas digan sus propias palabras, a fin de brindar un diálogo 
entre las adquisiciones culturales históricamente disponibles y lo que se ofrece aquí y ahora, en su ocasionalidad y en el flujo e interconexión de la vida en el mundo. Un diálogo entre las representaciones y las cosas mismas; entre ver y oír.

Palabras clave: Fenomenología; Ver; Escuchar; Diálogo.

\section{Introdução}

Este artigo se constitui de um ensaio, em que nos valemos de uma bibliografia para compor uma reflexão e uma meditação sobre nossa condição compreensiva no mundo, enfocando dois modos possíveis de entender, se relacionar e agir no mundo, com base nas metáforas do ver e ouvir. O ver fica associado com a atividade, com o controle, posse, fragmentação e domínio sobre as coisas. O ouvir, por outro lado, caracteriza mais a atitude receptiva, acolhedora, integradora, que permite ao outro ser-como-é. O enfoque fenomenológico existencial hermenêutico serve como pano de fundo das reflexões, bem como, algumas premissas estruturais e dinâmicas do psiquismo contidas no sistema teórico da Gestalt-terapia, sobretudo as concepções de ajustamento criativo e do ver e do ouvir como funções de contato.

A vivência que Husserl denomina de fenomenologia resgata e sistematiza a experiência do ouvir dando-lhe consistência teórica, apresentando o caminho do desapego, do colocar entre parênteses (da redução fenomenológica) o nosso saber acumulado, com a finalidade de retornar às coisas elas mesmas. Constata que nossos conhecimentos acumulados tinham se tornado uma lente com caráter de exclusividade no acesso ao real.

Nas palavras de Ortega e Gasset (1961), "na teoria permutamos a realidade por seu espectro, que são os conceitos” (p. 94). Diante do acúmulo histórico-cultural de ideias e visões em conceitos e teorias, tornamo-nos cada vez mais insensíveis para as coisas e experiências no seu acontecer vivo. Temos agora a tarefa de trilhar o caminho de retorno para a vida, ela mesma, mas sem recusar, obviamente, os progressos realizados. Esse caminho é próprio do herói, do artista e do místico (santo), que precisam reduzir, colocar entre parênteses, as imagens intelectuais, para poderem se abrir ao que se oferece aqui e agora na experiência viva.

A fenomenologia e a hermenêutica re-descobrem que a linguagem e o diálogo "pressupõe naturalmente a disposição de ouvir o outro, de prestar atenção ao que o outro quer dizer-me e que desafia minha compreensão” (Flickinger, 2012, p. 01). O outro não é somente aquele que não sou eu, mas sobretudo aquilo que não foi encapsulado, por ora, nas representações que temos disponíveis no saber compartilhado; o outro como possível, como o fluxo vivo que acontece nas profundidades das nossas tentativas de categorização e limitação nos conceitos e explicações. O outro é tudo o que se recusa ou ainda não foi assimilado e classificado racionalmente, justamente por manter-se conectado com o fluxo vital. Ou seja, que não foi objetivado a partir das lentes do conhecimento racional. Emerge, por isso, o desafio da "revitalização do ouvido como órgão mediatizador da verdade ante a prevalência moderna da visão que se manifesta, antes de tudo, pela insistência no princípio da objetividade científica" (Flickinger, 2010, p. 01).

Temos na fenomenologia e seus desdobramentos, como por exemplo na hermenêutica de Gadamer, a revalorização do ouvido. Nesse caminho, entretanto, nos "expomos ao risco de perder as certezas que vinham orientando nosso modo de viver e de nos relacionarmos com os outros" (Flickinger, 2010, p. 04). O controle, a segurança e a previsibilidade estão no conceito que segue o modelo da visão, da apreensão do real e sua representação. Aqui trata-se da "revalorização do ouvido como órgão que vem sendo negligenciado no decorrer da implementação da racionalidade instrumental” (Flickinger, 2010, p. 43). E o ouvido se aproxima metaforicamente da atitude receptiva, acolhedora, que deixa-ser e não submete imediatamente o que acontece aqui e agora às possibilidades abertas pela prévia visão de mundo mediadora da relação.

Exercitar o ouvir ao lado da visão permite, emprestando as palavras de Binswanger (2019) escritas em outro contexto, mas muito expressivas para o que estamos proferindo, "libertar o si mesmo de seus enredamentos em e de seus aprisionamentos nas imagens, nas quais ele sempre já vive de algum modo, exatamente como ele já sempre vive lá na esfera corporal”, (p. 49). 
Esse autor se preocupa com a limitação da compreensão da psicopatologia e psicoterapia ao horizonte do método científiconatural e encontra na fenomenologia possibilidade de alargamento desse horizonte.

Então, Flickinger (2010) afirma que,

em vez de apostar na capacidade exclusiva do olhar, como fundamento e meio do nosso acesso conhecedor ao mundo, o diálogo vivo faz jus ao ouvido como órgão de mediação de um saber inesperado. O diálogo vivo traz de volta o ouvido como fonte autêntica de nosso conhecimento (p. 43).

O diálogo abre para o outro, para o encontro e também o confronto. Quando a fala não é somente uma troca de informações que redunda num monólogo, ela transforma os envolvidos, coloca em questão os saberes e perspectivas prévios caso haja abertura autêntica para a escuta e o confronto com as visões vigentes. O diálogo autêntico é apresentado por Gadamer (2011) como o lugar onde pode acontecer a experiência em sentido fenomenológico. Diante do monólogo do ver, caracterizado por uma ontologia reducionista, o diálogo com o ouvir parece ser produtivo e enriquecedor. Uma conversa entre os olhos e os ouvidos.

Heidegger (1999) escreveu que normalmente reduzimos o pensar ao cálculo. Ora, calcular é eliminar o diálogo, pois os termos já estão sempre definidos e claros desde o início e se relacionam segundo regras fechadas. Ficar com o cálculo e as representações sobre a realidade nos deixa mais "seguros" para agir, receitar, julgar e prescrever; mas perdemos, com isso, a própria realidade que, por seu turno, a fenomenologia pretende reencontrar com a redução ou destruição (desconstrução) do edifício teórico e técnico que se interpõe entre nós e a realidade vivida. A vida no seu acontecer temporal não é exata. Somente a ordem introduzida pelos conceitos e pelas teorias, ao selecionar e classificar o acontecer, é que conferem à realidade previsibilidade e controle. Como a realidade se recusa ao enquadramento controlador, substituímos o mundo vivido pela representação e preferimos essa ao invés daquela.

Escreveu Heidegger que o "pensamento que calcula não é um pensamento que medita, não é um pensamento que reflete sobre o sentido que reina em tudo o que existe" (1999, p. 13). Unida ao pensamento que calcula, mesmo que encoberta, existe a capacidade de meditar e abrir-se receptivamente ao mundo. Há, portanto, na fenomenologia um apelo a nossa capacidade de ouvir com atenção. Confiamos demasiada e exclusivamente na visão, na clareza do foco e concentração e fomos perdendo a importante capacidade de escutar que conduz ao diálogo. Pela primazia do ver nos tornamos, em certa medida, "senhores" do mundo, "dominando" alguns dos seus segredos, para supostamente fazermos com que ele se "submeta" a algumas de nossas vontades. Com tal atitude perdemos a capacidade de ouvir o que ele também tem a nos dizer, sua conversa constante conosco e deixamos de reconhecer suas condições e seu próprio ser. Falamos o que as coisas são e não deixamos que elas pronunciem sua palavra.

\section{Metodologia}

O texto se configura como um ensaio, uma forma de construir-se uma argumentação sobre questões ligadas a várias ciências, por exemplo, a filosofia, as ciências sociais, e a psicologia. Meneghetti (2011, p 321) elenca que Marx, Weber, Norbert Elias, etc "Utilizam-se da forma ensaística para produzir reflexões sobre os acontecimentos mais relevantes da sua época:".

$\mathrm{O}$ estudo teórico e reflexivo reuniu autores e textos que permitem aproximações à discussão sobre as duas atitudes teórico-práticas em questão: ver e ouvir. Trata-se de uma análise sobre uma literatura clássica e atual de autores da Filosofia; da Psicologia Clínica; da Física Quântica e da Religião. A seleção de materiais visa arrazoar fenomenológicamente sobre as possibilidades do desenvolvimento de uma nova postura em relação ao mundo: escutar e reconhecer o outro.

Os autores principais utilizados na discussão foram Rorty (1991, 1994); Dahlke (2007); Capra (2013); Krishnamurti (1994); Flickinger (2010); Perls (1977); Perls, Hefferline e Godman (1997); Pimentel (2003). Há, no entanto, a presença também 
de outros como Aristóteles, Heidegger, Binswanger, Descartes, Eckhart, Fromm, Gadamer, Husserl, Jung, Nagel, Nunes, Ortega y Gasset, Santos e Stein.

O parâmetro epistêmico e analítico no ensaio objetivou realizar uma reflexão, nas proximidades das propostas fenomenológica e hermenêutica; e como pano de fundo o diagnóstico da atitude natural do ver e do ouvir pela qual, substituímos a realidade por representações e instituições e que, em função das urgências humanas e ecológicas, há que retornar para as coisas elas mesmas, para a experiência enquanto tal.

\section{Resultados e Discussão}

\section{Compreender e dar sentido a experiência de ver e ouvir}

Existimos compreensivamente no mundo. Ou seja, na relação com as coisas, com os outros e conosco mesmos, e temos consciência intencional dessas mesmas coisas, dos outros e de nós. Estamos abertos para o ser das coisas e dos acontecimentos, por meio da transcendência que o universo linguístico nos permite. Somos no mundo compreendendo o mundo e o que se passa dentro do mundo.

Nossos órgãos dos sentidos são vias de acesso ao universo exterior, mas precisamos da compreensão para dotar a experiência empírica de sentido. Isso porque "o objeto só nos é acessível através da mediação do significado [...] é da ordem da universalidade, de uma transcendentalidade, de uma aprioridade com a qual operamos" (Stein, 1997, p. 86). Entender das coisas significa, dessa forma, uma intimidade prévia com uma totalidade de significados. O que as coisas são para nós não provém diretamente da natureza das coisas, mas da abertura compreensiva com a qual estamos na luminosidade do mundo.

Nunes (1992) escreve que

o conhecimento, enquanto correlação irreversível do sujeito e do objeto - do sujeito que apreende o objeto e do objeto que determina as representações do sujeito - só é possível mediante a transcendência da conduta, que se espraia no mundo sem estar dentro dele (p. 73).

Nosso comportamento explicativo e teórico não se dá de forma natural no sentido de entrar numa relação de espelhamento da verdade dos objetos (Rorty, 1994). Nossa relação explicativa e representativa implica numa prévia situação compreensiva no mundo e do mundo.

Como não podemos nos colocar na posição do conhecimento do olho de Deus, havemos de reconhecer a condição finita e situada de todo saber e fazer humanos. Não alcançamos a visão a partir de lugar nenhum (Nagel, 2004) que nos permita objetividade no conhecimento. A fenomenologia e hermenêutica insistem que somos ser-no-mundo (Heidegger, 2006), envolvidos e mergulhados num tempo e lugar cultural específicos; somos históricos e falamos uma determinada língua. Estamos desde o início comprometidos com uma compreensão histórico-cultural do que é real e verdadeiro. Não podemos recusar essa situação inicial, pois é ela mesma que nos coloca em contato com as coisas enquanto tais. Mas podemos exercitar e nos aproximar, com um esforço de meditação e apropriação dessas condições normais, uma mobilidade ou distanciamento progressivo que permita experimentar além das possibilidades oferecidas pelo contexto atual, pelas explicações e teorias que nos ordenam e apresentam as coisas dessa forma e não de outra.

Nosso acesso ao mundo é sempre mediado por uma rede de sentido que não é o mesmo em tempos e lugares diferentes. E a fenomenologia surge com a proposição de que nossa consciência é intencional; e que o que sabemos sobre as coisas é aquilo que a rede consegue captar e guardar. Estamos limitados pelo que sabemos. Conhecemos com o conhecimento que já temos. Somos carregados pela compreensão do nosso tempo e lugar. Ou seja, "cada existência histórica está imersa em tradições que a antecedem e que passam a ser seu senso comum, delineando possibilidades de ser” (Evangelista, 2016, p. 39). 
Com a metáfora do ver e do ouvir que apresentamos agora, pretendemos tornar mais clara a constatação realizada pelo pensar fenomenológico e também indicar desafios para nossa relação cognoscitiva e prática no mundo. $\mathrm{O}$ ver e ouvir são metáforas e não conceitos objetivos. Entendemos que a metáfora tem um papel importante quando o que conta é retornar para a vida ela mesma, para o acontecer das coisas na sua ocasionalidade. Escreve Richard Rorty (1991) que,

as metáforas visuais contrastam com as metáforas auditivas preferidas por Heidegger (por exemplo, Ruf des Gewissens, Stimme des Seins). As últimas são melhores metáforas para a metáfora, pois sugerem que o conhecimento nem sempre é reconhecimento, que a aquisição da verdade não é sempre uma questão de encaixar informação num esquema preestabelecido. Uma metáfora é, por assim dizer, uma voz que vem de fora do espaço lógico [...]. É um chamamento para que mudemos a nossa linguagem e a nossa vida, em vez de uma proposta de como haveremos de sistematizar ambas (p. 30 - 31).

Os conceitos ou categorias, por sua vez, constituem representações ideais que são tanto mais claros e inequívocos quanto mais conseguem se desligar do fluxo temporal do acontecer das coisas, da vida vivida. Ortega y Gasset (1961) notou que "na teoria permutamos a realidade por seu espectro, que são os conceitos" (p. 94). Husserl (2012), ao escrever que "queremos retornar às "próprias coisas" (p. 05), reivindica o valor e prioridade do vivido em relação ao espectro conceitual. Trazer a vida do plano racional para o plano do dar-se à consciência. Por isso o apelo para que a linguagem não seja reduzida a representação especular, mas entendida como 'indício formal' ou como 'existencial' na linguagem de Heidegger (2006, 2013), ou seja, permaneça no universo da metáfora. É isso, em certa medida, que também Jung tem em mente com a sua discussão sobre o símbolo.

$\mathrm{O}$ ver representa metaforicamente o ideal da racionalidade, da clareza e evidência teóricas que, por sua vez, permitem circunscrever e dominar o real de forma mais efetiva e eficaz. O ouvir toma, em nossa reflexão, o lugar do efêmero e circunstancial do que acontece aqui e agora. O ideal sobretudo moderno é livrar-se o quanto possível da totalidade de remissões, conexões (contexto) das coisas e do seu perecimento temporal através da fixação em conceitos e explicações que diferenciam uma coisa da outra de forma cada vez mais precisa.

Para 'retornar às coisas mesmas' é necessário mergulhar de volta para o acontecer vivo onde tudo está ligado e pertence a uma conexão ampla. Trata-se de permitir experimentar as coisas em seu contexto, no envolvimento, ou seja, no todo. Envolverse é perder a segurança da distância e da diferença, algo pouco apreciado num mundo que preza pela objetividade que planeja, controla e prevê tudo de forma ampla. Na imersão no todo, no contexto, podemos nos perder e dissolver, justamente o que o esforço de racionalização da realidade busca impedir.

Lembramos que as atitudes teóricas e práticas podem estar, por analogia, ancoradas em potenciais específicos de alguma faculdade humana em particular, como a visão e audição. Talvez até pudéssemos falar de uma cultura do (com) tato, do paladar ou do olfato, mas o que foi, e prossegue predominante, atualmente na cultura do espetáculo e das tecnologias de informação e comunicação, desde a modernidade são os modos de viver e entender o mundo que se organizaram em torno da visão e audição. E, ao que parece, o Ocidente valorizou mais a visão, enquanto o Oriente a audição. Sobremaneira aquilatamos o conhecimento ligado ao ver nos processos de conhecimento ocorridos no Ocidente. Esse sentido acabou por se sobressair diante do ouvir e dos outros sentidos, talvez por permitir aproximar-se mais do ideal de conhecimento moderno.

Visão e audição são duas janelas que estão no corpo e nos abrem e conectam com o mundo externo; prosseguem, supostamente, nos oferecendo acesso privilegiado à realidade. Distinguindo-as nos dispomos a pontuar a possibilidade e, quem sabe, a necessidade de juntarmos diversos enfoques de conhecimento, de forma a enriquecer e ampliar nossa experiência do mundo e de nós mesmos. Não se trata de valorizar ou desvalorizar uma em relação à outra, mas reivindicar a complementariedade entre seus potenciais. Cada uma representa um polo na dinâmica da existência: ação e contemplação; atividade e passividade; masculino e feminino; objetividade e subjetividade; análise e síntese; razão e intuição; tempo-cronos e tempo-kairós; domínio e 
serenidade; quantidade e qualidade. $\mathrm{O}$ ver e ouvir representam duas atitudes que tem lugar na história humana. Essas atitudes caracterizam modos diferentes de compreender, agir, se posicionar e orientar na vida, inclusive de entender o normal e o patológico, a saúde e a doença.

\section{Mundo e conhecimento a partir do ver e ouvir}

Se perguntássemos às pessoas com qual sentido (visão, audição, tato, paladar e olfato) mais se orientam no mundo, ou em qual mais confiam - possivelmente teríamos como resposta a visão. Esse parece ser o sentido mais adequado para se sentir confiável e seguro no mundo. Quando não vemos, ficamos perdidos, desorientados. Um cego tende a, provavelmente, assim que entra num ambiente, criar uma imagem mental para poder se orientar. Ele começa a se sentir protegido na medida em que completa e confirma a imagem ou visão interior. Embora os outros sentidos também nos ajudem na orientação entre as coisas, a perceber os perigos, a detectar o ambiente, é a visão que mais confere segurança aos nossos movimentos, nossa orientação no espaço.

E no nosso comportamento teórico e prático, na relação compreensiva com as coisas, com o mundo e conosco mesmos, ao fazermos pesquisa, ao cuidarmos das pessoas, ao realizarmos escolhas éticas, estéticas, religiosas, políticas e tudo mais, nos conduzimos a partir da confiança que temos em uma imagem naturalizada e prévia do que seja o mundo. O quadro lógico e linguístico em que nos movemos tem pressupostos ou modelos que orientam nosso existir. E a conjectura que aqui enfatizamos é aquela que se expressa na metáfora da visão. Ao menos desde Aristóteles, criou-se a convicção de que o conhecimento adquirido pela visão "merece" mais crédito. Que há uma ligação entre saber e visão. Vemos o mundo e nos causa admiração e, a partir de então, buscamos alguma explicação. Lembremos que o começo da filosofia é a admiração. Caminho da filosofia foi: ver, admirar, refletir.

Inclusive a v palavra 'ideia' procede do grego 'idea', que significa 'aparência' ou 'forma', que remetem diretamente ao 'ver'. Em Platão a visão gera a recordação do protótipo ideal. Em Aristóteles (2002), a visão produz a admiração reflexiva. Recordemos o que escreve Aristóteles no início da Metafísica:

Todos os homens, por natureza, tendem ao saber. Sinal disso é o amor pelas sensações. De fato, eles amam as sensações por si mesmas, independentemente da sua utilidade e amam, acima de todas, a sensação da visão. Com efeito, não só em vista da ação, mas mesmo sem ter nenhuma intenção de agir, nós preferimos o ver, em certo sentido, a todas as outras sensações. E o motivo está no fato de que a visão nos proporciona mais conhecimentos do que todas as outras sensações e nos torna manifestas numerosas diferenças entre as coisas $(980-25$, p. 03).

Temos em Aristóteles a afirmação clara da preferência da visão e da sua primazia no conhecimento. E na medida em que o pensamento grego conformou e marcou fortemente os contornos do nosso modo de ser e pensar ocidental, a visão se tornou o sentido por excelência. Dizemos 'visão de mundo', 'visão filosófica', 'visão científica', 'visão interior', etc, mas não dizemos 'audição de mundo', 'audição filosófica', 'audição científica', 'audição interior', etc. (nem 'paladar do mundo', 'cheiro do mundo', 'sensação do mundo').

A modernidade se inaugura com a reivindicação de Descartes (2001) de clareza e distinção como critérios de evidência que se realizam na visão, que tem relação com a luz e a vidência. $O$ critério do conhecimento é que possua clareza e evidência. Ou seja, a metáfora da visão se tornou nossa referência preferencial no conhecimento. Para Rorty (1991), temos a

[...] pressuposição de que a verdade tem algo a ver com evidência, com ser-se claro e convincente, com o estar-se em posse de argumentos ou visões poderosas, penetrantes, profundas - visões ou argumentações que nos colocarão numa posição de liderança face a face com qualquer coisa ou qualquer pessoa (p. 59). 
Rudiger Dahlke (2007), um médico e pesquisador alemão contemporâneo, estabelece relações entre as condições anatômicas e as compreensões arquetípicas relacionadas ao ver e ouvir. Escreve ele que "por sua aparência externa, os olhos correspondem ao Sol e ao princípio masculino. [...] Já o órgão auditivo, ao contrário, impressiona externamente através do pavilhão auricular, que simbolicamente está próximo da Lua e do princípio feminino" (p. 113). Uma aproximação possível é, portanto, entre o ver e ouvir e os princípios masculino e feminino. A experiência de que o universo é movido pela tensão entre dois polos da realidade esteve sempre presente na sabedoria dos nossos ancestrais. Essa polaridade recebeu diversos nomes e, entre esses, temos yin e yang, masculino e feminino, sol e lua. Essas são importantes metáforas para representar essa tensão, como podemos verificar, por exemplo, nas imagens de transformação descritas na alquimia (Jung, 2013).

Dahlke (2007) também constata que na dimensão fisiológica,

Os olhos são a única parte de nosso corpo onde o cérebro se torna visível [...] são parte do sistema nervoso central. Devido à sua própria natureza, visão e consciência estão naturalmente ligadas. A promoção dos olhos a órgão dos sentidos de primeira classe ocorreu juntamente com a primazia conquistada pelo cérebro. O pensamento impregna nossa visão, mas a visão também impregna o pensamento. Um corresponde ao outro em suas possibilidades e fontes de erro e se promoveram mutuamente (p. 114).

A visão está orientada pela luz, pelo Sol, cujos raios parecem tomar sempre o caminho reto e mais curto, e por isso está ligada ao pensamento linear e sem rodeios (Dahlke, 2007). Baseado nisso, nosso pensar adota também a lógica linear, direta e o caminho mais curto. A racionalidade objetificadora em que vivemos, com perspectiva mecanicista e fragmentadora, se orienta justamente pela visão e pela luz, pela linearidade que não tolera devaneios, voltas, curvas, esferas. Com isso "nós favorecemos a visão em prejuízo da audição e colocamos nossa razão cristalina em primeiro lugar” (Dahlke, 2007, p. 114). Ou seja, a racionalidade ocidental, que constitui nossa consciência, tem na visão e naquilo que a visão permite, a luz para decidir em relação ao conhecimento, a valores, a escolhas em geral. Preferimos usar a razão para escolher, decidir e depreciamos a intuição, a sensação e o sentimento, pois são muito subjetivos. A voz do coração não tem muito "prestígio" para a produção do conhecimento, pois não obedece matematicamente e rigorosamente a lógica do isto ou aquilo e da linearidade. A intuição também não recebe muito crédito, pois não lida com evidências. Nas palavras de Fritjof Capra (2013):

Nossa cultura tem favorecido, com firmeza, valores e atitudes yang, ou masculinos, e tem negligenciado seus valores e atitudes complementares yin, ou femininos. Temos favorecido a autoafirmação em vez da integração, a análise em vez da síntese, o conhecimento racional em vez da sabedoria intuitiva, a ciência em vez da religião, a competição em vez da cooperação, a expansão em vez da conservação, e assim por diante (p. 23).

Nesse sentido, Dahlke (2007) chama a atenção para o fato de que a visão também é problemática:

Nós não vemos igualmente bem e com a mesma nitidez em toda superfície da retina. [...] A visão tornou-se para nós um ato de concentração, pois nós fixamos o olhar em um ponto, permitindo assim, que o resto fique automaticamente fora do foco (p. 114).

A visão é centrada, focada. Exclui parte do que está no ambiente e desfoca parcela significativa do que está no campo de visão. Para que uma coisa se torne nítida, ou seja, clara e evidente e, de preferência também exata e inequívoca, é preciso deixar na penumbra o ambiente geral dentro do qual o objeto sob enfoque se encontra. Exige-se, como condição da racionalidade do conhecimento, deixar de lado, com base em critérios metodológicos e teóricos prévios, o contexto e conexões que, se mantidos sob enfoque, tornariam o objeto anterior incerto e borrado.

Além do mais, o olho tem "um ponto cego próximo ao ponto em que a visão é mais aguçada, o local onde o nervo ocular 
penetra na retina" (Dahlke, 2007, p. 115). Assim também a consciência "treinada para escolher e para adotar pontos de vista unívocos e a seguir racionalmente o caminho mais curto, tem igualmente outros tantos pontos cegos" (Dahlke, 2007, p. 115). A exatidão somente é possível abdicando de uma visão mais ampla e profunda. A clareza do conhecimento acontece às custas da própria realidade. Conhecemos bastante bem e com precisão objetos isolados, resultado da nossa crescente especialização, mas não podemos dizer que com isso conhecemos a própria realidade. Se borrássemos as fronteiras de todos os conhecimentos específicos, eles tornar-se-iam problemáticos. Souza Santos (2010) escreve que quanto mais exato um conhecimento, menos realidade ele contém.

E Dahlke (2007) continua:

O olho, portanto, fornece a base tanto para a racionalização como para a projeção, favorecendo nossas valorações e promovendo a escolha e, com ela, a limitação do mundo. Como ele faz tudo isso a serviço do pensamento e sua visão de mundo, linear, racional e avaliadora, a consciência se vinga com um artifício ousado: ela sugere que todas as percepções de nossos olhos são objetivas, ou seja, que aquilo que nós imaginamos lá fora corresponde à realidade (p. 115).

Essa crença na objetividade do conhecimento corresponde à noção da mente como espelho da natureza, discutida por Rorty (1994). Essa visão deixa de lado a condicionalidade e contextualidade, o reconhecimento de que o conhecer se desenvolve dentro de uma situação compreensiva. Que o ver dos objetos enquanto isto ou aquilo necessita de uma luz, ou seja, de um universo de sentido que ofereça a densidade de um ambiente onde identidades e diferenças sejam possíveis. Assim, "nossa visão de mundo e o predomínio do intelecto estão baseados nesse truque. Em última instância, isso se deve aos olhos e seus esforços de endireitar artificialmente o mundo redondo" (Dahlke, 2007, p. 115). O truque inclui a estratégia de eliminar a circularidade que há entre aquilo que sabemos e o que nos permite o saber. Endireita-se a circularidade, eliminando os pressupostos e olhando sempre para frente, o que resulta no movimento linear. Aí podemos sempre andar como se as condições prévias que nos constituem e sustentam nosso saber sejam inquestionáveis e irrecusáveis.

Temos aqui caracterizado o esforço de eliminação da subjetividade que a ciência moderna demanda. Somente com a neutralização do polo do sujeito, com suas idiossincrasias e envolvimentos, o conhecimento alcança objetividade. Essa expectativa, no entanto, mostra-se cada vez mais irrealizável, pois experimentamos fortemente a implicação profunda entre o observador e a realidade (Heisenberg, 1996), de modo que o ver é sempre relativo a uma situação humana no mundo.

Tendo a visão como referência, enfatizamos o poder e domínio racional sobre o espaço e as coisas. Minimizamos a escuta, que tem um cunho mais receptivo. A visão é ativa. Tendo o ver como mais importante, gesta-se um modo de estar-nomundo que é dominador, possessivo, controlador e ativo. Buscamos a segurança e fugimos do inseguro; queremos a certeza e verdade, e não a dúvida; queremos respostas e não perguntas; buscamos resultados e não contemplação. Resulta que agimos e falamos tanto sobre o mundo e as coisas, que o projeto que surge dessa ação e discurso, se autonomiza e naturaliza como 'a' realidade. Substituímos o real pela representação conceitual.

Atrofiamos a capacidade de escutar, embora nossos ouvidos funcionem bem. Nosso ouvir se limita ao possível do que já sabemos e de ajustes e correções internas. Tudo tende a ser subsumido na teoria, na ideia, na visão. Do pensar e agir a partir do modelo visual decorre a submissão da realidade às visões teóricas, ou seja, produz-se certa violência que obriga a natureza a ser e corresponder a nossos projetos, imagens ou visões de mundo. Carecer do escutar resulta na indiferença, nivelamento e tendência de eliminação de toda alteridade. Agimos ansiosamente para transformar o mundo a fim de que se assemelhe às imagens do que deveria ser em nossa mente. Não perguntamos nada a ele, pois nos colocamos acima e não estamos dispostos a escutar o que tem a dizer. Ver sem escutar nos sobrecarrega e satura de imagens, verdades, opiniões. E estas, por sua vez, se tornam o pressuposto para todos os novos empreendimentos teóricos. Ou seja, que "na medida em que nossa representação da realidade é muito mais fácil de se apreender que a realidade propriamente dita, tendemos a confundi-las e a fazer com que nossos conceitos e símbolos se 
tornem equivalentes à realidade" (Capra, 2013, p. 42). Isso nos livra de questões que trariam um emaranhamento que não teríamos como resolver com os artifícios de uma razão lógica e mecânica e que nos levariam para outros caminhos de conhecimento e relacionamento.

E no contexto da virtualidade o olhar voyeur se amplifica; as imagens de beleza, de felicidade e de representações são potencializadas. Igualmente, nos cenários das redes sociais virtuais são delineados colapsos e declínios das relações interhumanas e da dignidade, trazidos pelo império da imagem e da comunicação narcísica. Configuram abusos e descomedimentos na comunicação virtual e se tornam metáforas presentes nas representações do uso da internet.

O indiano Krishnamurti (1994), que viveu muito tempo no Ocidente e se tornou um grande mestre do viver afirma, dentro da perspectiva linear, que "o pensamento, através do próprio processo de pensar, se condiciona a si mesmo" (p. 11). Para ele:

A mente que realmente consegue entender o problema é a mente simples, e não a mente sofisticada, a mente atravancada de conhecimentos. [...] tentemos escutar [...] sempre abordamos nossos problemas com asserções, pressupostos e conclusões. [...] A revolução fundamental é desfazer o conhecimento; [...] Porém, a maioria das pessoas aborda a vida com o conhecimento. [...] O conhecimento se torna a autoridade, o guia que nos mantém no santuário da sociedade, nas fronteiras da respeitabilidade. O conhecimento é o centro a partir do qual julgamos e avaliamos, a partir do qual condenamos, aceitamos ou rejeitamos (p. 16 e 17).

Ou seja, aquilo que sabemos estabelece previamente os limites do que conseguimos acessar do real. O conhecimento que acumulamos nos dá poder e domínio. E parece ser, no mínimo, constrangedor questionar este e aquele conhecimento e arriscarse a perder, assim, o poder. O conhecimento que possuímos (que, mais frequentemente, nos possui) é ele mesmo o acesso ao mundo. Ele é a própria visão do mundo, é o nosso olho. E continua:

O conhecimento é condicionado. O conhecimento não dá liberdade. [...] O pensamento não é o fator criativo, porque o conhecimento é contínuo e o que tem continuidade não pode levar ao implícito, ao imponderável, ao desconhecido. O conhecimento é um empecilho ao que é aberto, ao desconhecido; o conhecido sempre se move para o passado e este se sobrepõe de modo contínuo ao presente, ao desconhecido. Sem liberdade, sem uma mente receptiva, não pode haver compreensão. A compreensão não vem com o conhecimento; ela vem nas entrelinhas, no intervalo entre os pensamentos. Esse intervalo é o silêncio não quebrado pelo conhecimento; é o aberto, o imponderável, o implícito (Krishnamurti, 1994, p. 23).

Quanto a audição ponderamos a importância de incluir o silêncio como situação pertencente à audição. A vivência intencional das coisas mesmas e das relações carrega o silencio, a serenidade que é capaz de acolher o inusitado. Na cotidianidade nos apressamos e esforçamos por revestir tudo o mais rápido possível com os rótulos que estão nos nossos catálogos. Para não sentir a perturbação e os inconvenientes de ouvir uma voz ou um som não classificado, nos antecipamos com nosso saber. Isso é que Krishnamurti (1994) chama de passado, aquilo que nossa cultura, nossa ciência e nossas crenças acumularam e se tornou tradição.

A passagem da quase exclusividade do ver, que nos garante clareza e evidência lógica, além de um domínio e controle significativo sobre a realidade, para o ouvir, não é uma atitude muito confortável. Não é acaso que na linguagem religiosa se fale de um processo de mudança e conversão, uma transformação usualmente dolorosa, pois implica a destruição e desapego daquilo que assegura nossa identidade, ou seja, nosso eu; exige a morte para a consciência anterior. E trata-se da morte daquilo que diferencia e separa, a fim de retornar para a unidade e comunhão consigo e com o mundo como um todo. Um retorno ou mergulho no fluxo vivo do acontecer das coisas, que dilui inclusive a subjetividade objetivada.

Apesar da predominância do modelo da visão em grande parte do mundo ocidental, há também tradições e experiências que valorizam a audição. Na Bíblia encontramos a poética afirmação: "no início era o Verbo" (João 1, 1); Dahlke (2007) lembra 
que os Vedas proclamam que "tudo surgiu a partir da sílaba primordial OM", e que "na concepção dos aborígenes da Austrália, Deus cantou o mundo. Até mesmo em nosso mundo desencantado a física ensina que o universo surgiu a partir de um estrondo primordial” (p. 114). O som, a vibração, o ritmo, estão, nessas tradições, ligadas ao ser da realidade.

Nos caminhos de desenvolvimento humano e na mística o exercício do ouvir é também reivindicado e, com ele, a necessidade de descarregar-se das imagens e ideias prévias para avançar, por exemplo, na experiência do divino e de amadurecimento pessoal.

Ouvir fenomenologicamente significa o 'deixar ser', abrir-se para a coisa ela mesma, permitir um acesso não sobrecarregado por mediações ideais. Não é por acaso que se enfatiza a 'pobreza interior' e 'desapego'. Por exemplo, Meister Eckhart (2016), falando da pobreza espiritual, pensa no homem pobre como "aquele que nada sabe [...] vazio de todo conhecimento" (p. 76). Na experiência dos místicos a questão da pobreza, do desprendimento, do esvaziamento, do desapego são muito importantes; quem quiser se aproximar do divino precisa se desapegar das ideias ou imagens que já tem e que herdou da tradição. Somente esvaziando-se é possível permitir acesso às coisas elas mesmas, no seu acontecer ocasional. Ninguém alcança o 'outro', seja Deus, outra pessoa, as coisas e acontecimentos, sem passar por um processo de empobrecimento que retira as mediações, os acessos institucionais e teóricos que até o momento compõe nossa consciência.

\section{Criar e atualizar sentidos gestálticos no ver e no ouvir}

Quando Frederick Salomon Perls e seus colaboradores propuseram a abordagem gestáltica do psiquismo, definiram como pressuposto a importância de captar como um fenômeno psicológico ocorre, abordando-o em sua totalidade, ou seja, focalizando os aspectos estruturais e dinâmicos do psiquismo. As referências são as obras clássicas Yo, hambre y agresión (Perls, 1975) e Gestalt-terapia (Perls, Hefferline \& Goodman, 1977).

Perls considerava a percepção "uma atividade e não uma simples atitude passiva". Coerente com esta circunscrição, o pensamento sobre a psicoterapia baseia-se na busca da compreensão da dinâmica presente nas estruturas do psiquismo. Em conclusão, o ver e o ouvir se organizam nas formas de olhar e escutar constantemente, em acordo com as vivências e os contextos, em prol do ajustamento criativo das existências, um dos pilares do sistema Gestáltico para a elaboração dos conceitos de Saúde e de adoecimento psicológico e mental na prática clínica, bem como os fundamentos fenomenológicos, existenciais e hermenêuticos. Sua utilização é associada ao emprego de um conceito de saúde mental orientado pela integralidade. Criar implica fortalecer os auto suportes das pessoas para que realizem o contato pleno, aquele em que se dá a satisfação das necessidades e a realização do processo de se concentrar, se envolver e fechar a Gestalt ou situação inacabada e passar a outro movimento na dinâmica de comunicação recíproca com o outro e com o mundo (Polster \& Polster, 2001).

Frederick Perls nomeou de ajustamento criativo o predicado do contato que o indivíduo mantém na fronteira organismo/ambiente, objetivando sua autorregulação sob diversas condições. Não é mera "adaptação". D’ Acri, Lima e Orgler (2007, p. 20) consideram que a qualidade "criativo" diz respeito ao ajustamento "resultante do sistema de contatos intencionais que o indivíduo mantém com seu ambiente".

Ao considerarmos a noção de intencionalidade para compreensão das vivências das pessoas, nos confrontamos com as normas deliberadas de exclusão social que geram os ajustamentos conservadores, dada as circunstâncias sociopolíticas e econômicas do mundo, em que as vivências são socializadas, o que representa as impossibilidades originárias do vir a ser criativo em nosso entorno social, mantendo o ver e o ouvir cristalizados em significações padronizadas (Pimentel \& Castro, 2019)

No contraponto dos ajustamentos conservadores, as pessoas ao realizarem o ajustamento criativo, desenvolvem métodos para viver e crescer, atuando de forma ativa e responsável, no sentido de providenciar seu próprio desenvolvimento, e conseguintemente, suas necessidades físicas e psicossociais, superando as disfunções de contato. 
Perls (1975) especificou que a formação do cientista e do Psicólogo deveria basear-se na compreensão do ser humano como uma totalidade; e juntamente com Hefferline e Goodman (1997) que a intervenção clínica contribuísse para facilitar condições para que os clientes percebessem e afirmassem vínculos entre suas ações e os sentidos das mesmas, visando a regulação pessoal e o entendimento da condição humana.

Pela via do movimento dialógico entre a assimilação e a alienação das informações recebidas do e no mundo, as pessoas podem realizar o contato criativo, conceito que para Erving Polster e Miriam Polster (2001) diferencia-se de companhia e de agrupamento por ser a capacidade de unir-se a alguém ou a algo, afastar-se discriminado os sensos do próprio eu, das coisas e do ambiente por meio da fronteira de contato.

As fronteiras e as funções de contato criativas resultam no fortalecimento da identidade psicológica autônoma, original e singular. Particularmente, aqui nos atemos às funções de contato do olhar e do ouvir. É essencial destacar que tanto a noção de fronteira como a de funções referem-se ao movimento da corporeidade, não ao corpo estático. Portanto, ponderamos sobre o corpo vivido, a experiência no mundo, o modo de ser no mundo, potência expressiva (Alvim et al, 2012)

Escutar é objetivo presente no movimento de reconhecimento do outro. É uma postura relacional e uma prática clínica; ambas caracterizadas pela decodificação dos significados do dito, nas várias linguagens usadas pelas pessoas e pelo cliente: verbal, corporal, artística. Nossa tarefa é desmontar as camadas de significados contidos na representação social, que somente aponta o que está fora de nós, ou seja, os modelos de persona; as vozes criticando condutas, os ruídos entre o que sentimos e as prescrições sobre como devemos "ser", etc.

\section{Considerações Finais}

Nossa proposição foi de alinhavar argumentos para tecer uma crítica acerca da atitude natural que embota nossa capacidade de escuta, pois o ver predomina no contato e nas relações sociais. E, mais do que isso, o ver caracteriza a lógica, a gramática e o conteúdo que informa nossa consciência no mundo. Por isso, a atitude auditiva provoca e coloca em questão a atitude ótica. Compreendemos que o resultado da predominância da visão é que submetemos o mundo ao projeto que nós, humanos, inventamos, tornando, aos poucos, nosso comportamento um perigo para a vida no planeta e para o reconhecimento e dignidade da vida humana. Vamos longe submetendo a natureza às nossas exigências e silenciando os seus apelos e movimentos. O avanço teórico e técnico, o acúmulo de informações sem o desenvolvimento da sabedoria que implica em abertura e serenidade, adoece a nós e ao mundo.

O acúmulo e enxurrada de informações não produz um conhecimento mais profundo e amplo da realidade; aumenta o hiato entre nós e mundo, pois amplia as mediações e diminui a possibilidade de envolvimento e a aproximação das coisas elas mesmas. $\mathrm{O}$ avanço linear do conhecimento e das técnicas diminui a capacidade de escuta. Por isso a fenomenologia procede a um retorno, uma volta pra casa, que é justamente uma reaproximação das coisas no seu acontecer, ao mundo no seu movimento vivo. Mas, com isso, não se pretende negar o conhecimento que resulta da visão, mas afirmar a necessidade de colocá-lo em diálogo com a vida vivida. Afirmamos então a necessidade de uma 'audição de mundo' ao lado da 'visão de mundo'. Reconectar-se com e ao ouvido. Ouvir o que o corpo diz com seus sinais. Se apenas olharmos para o corpo, trataremos de separar e estabelecer relações de causalidade lógicas e trabalharemos para eliminar o que não combina. Ouvir o corpo implica em `suspender’ nossas 'teorias' e explicações prévias para estarmos dispostos para a ocasionalidade em suas vozes.

O movimento fenomenológico não se constitui de um conjunto de conteúdo, saberes ou teorias que devam ser defendidas e perpetuadas. Nem um novo método que nos dá acesso à verdade dos objetos que antes estava velada ou vedada. Ele é um exercício reflexivo e o desenvolvimento de uma atitude de abertura e disponibilidade para as coisas elas mesmas. Isso exige a disposição para desconstruir, desapegar-se, empobrecer-se das visões, das imagens e representações. Em última análise, é um 
caminho de autoconhecimento pois atenta para a consciência intencional, lugar do acesso aos objetos. É um retorno ao vivido de cada experiência, que funda os conceitos e teorias, para, dessa forma, poder morar nas proximidades do originário.

É o aprendizado da integração, reconciliação ou casamento entre o ver e ouvir, o feminino e o masculino, as sombras e as luzes, a atividade e a receptividade, entre yin e yang, entre a mente e o mundo, entre consciente e inconsciente, além de outros binômios; um caminho de reconhecimento de que nossa consciência funciona a partir da dualidade, mas que carrega no fundo da alma a provocação e o desejo de repousar na integração amorosa com tudo. Propõe que, ao invés de nos apegarmos a um dos extremos das oposições, tornando-as excludentes, nos esforcemos por integrar, através do diálogo, as duas forças aparentemente opostas. Não se propõe a eliminação da visão, mas um ver aberto e que se corrige continuamente na escuta do vir-a-ser da realidade. Uma profunda confiança na vida, onde os princípios representados pela visão e audição possam dar as mãos, ativa e serenamente, como opostos complementares.

A forma de contribuir cientificamente organizada em nossa reflexão é a interrogação, posta aqui nas perguntas: o que fazemos para integrar e equilibrar melhor em nós as dimensões que aparentemente se opõe? Podemos ser mais plenos, profundos, humanos, saudáveis e amadurecidos com esse trabalho? E entendemos que o desenvolvimento daquilo que foi chamado de atitude fenomenológica é o exercício e constante preparação para a reconciliação entre as diversas potencialidades humanas, não excluindo a capacidade representacional do conceito e da teoria, mas aliando-se a outras possibilidades e experiências e, especialmente, aprendendo a aceitar e reconciliar em nós e no mundo as dimensões aparentemente opostas, mas que são complementares.

Ouvir permite desenvolver o potencial de experimentar o que vai dentro de cada um, aproximando-se das vivências de ansiedade, dúvida, curiosidade, indagações, etc. Torna possível acolher e escutar a si mesmo, às outras pessoas e às circunstâncias. É gestar a abertura que acolhe os sentidos intersubjetivos; a afirmação da condição humana de sujeitos envolvidos e comprometidos. Nossas pesquisas qualitativas e ensaios refletem acerca da condição humana e ensejam contribuir com subsidios teóricos para outros profissionais e pesquisadores deste campo temático.

\section{Referências}

Alvim, M. B., Araújo, D. V., Baptista, C. S., Barroso, F. T., Queiroz, K. M. F., \& da Silva, T. C. D. (2012). Corpo, fala e expressão: diálogos entre a Gestaltterapia e a filosofia de Merleau-Ponty Body, speech and expression: dialogues between Gestalt therapy and Merleau-Ponty. IGT na Rede, 9 (17).

Aristóteles. (2002). Metafísica. Loyola.

Bíblia. (1996). Tradução Ecumênica. Edições Loyola e Paulinas.

Binswanger, L. (2019). Psicoterapia e análise existencial. Via Vérita.

Capra, F. (2013). O Tao da Física. Cultrix.

Dahlke, R. (2007). A doença como linguagem da alma. Cultrix.

Descartes, R. (2001). Discurso do Método. Martins Fontes.

D’Acri, G.; Lima, P. \& Orgler, S. (2007) Dicionário de Gestalt-terapia: “Gestaltês”. São Paulo : Summus Editorial.

Eckhart, M. (2016). A nobreza da alma humana e outros textos. Vozes.

Evangelista, P. E. R. A. (2016). Psicologia fenomenológica existencial. A prática psicológica à luz de Heidegger. Juruá.

Flickinger, H. (2010). A caminho de uma pedagogia hermenêutica. Editores Associados.

Fromm, E. (2014). Ter ou Ser? LTC.

Gadamer, H. (2011). Verdade e Método II. Petrópolis: Vozes, Bragança Paulista: Editora Universitária São Francisco.

Heidegger, M. Serenidade. (1999). Instituto Piaget.

Heidegger, M. (2006). Sein und Zeit. Tübingen: Max Niemeyer Verlag. 
Research, Society and Development, v. 10, n. 3, e60010314154, 2021

(CC BY 4.0) | ISSN 2525-3409 | DOI: http://dx.doi.org/10.33448/rsd-v10i3.14154

Heisenberg, W. (1996). A parte e o todo: encontros e conversas sobre física, filosofia, religião e política. Rio de Janeiro: Contraponto.

Husserl, E. (2012). Investigações Lógicas. Forense.

Krishnamurti, J. (1994). Sobre a aprendizagem e o conhecimento. Cultrix.

Meneghetti (2011). O que é um Ensaio-Teórico? Documentos e Debates:RAC, 15(2), 320-332.

Nagel, T. (2004). Visão a partir de lugar nenhum. Martins Fontes.

Nunes, Benedito. (1992). Passagem para o poético - filosofia e poesia em Heidegger. Ática.

Ortega e Gasset, J. (1961). Que é filosofia. Livro Íbero-Americano Ltda.

Perls, F. S. (1977). Yo, Hambre Y Agresion. Fondo de Cultura Econômica.

Perls, F.; Hefferline, R. F. \& Goodman, P. (1997) Gestalt-Terapia. Summus.

Pimentel, A (2003). Psicodiagnóstico em Gestalt-terapia. Summus.

Pimentel, A. \& Castro, E. H. B. (2019). Ajustamento criativo e enfrentamento a subalternidade por mulheres negras e lésbicas. Pluralidades em Saúde Mental, Curitiba, 8(1), 113-126.

Polster, E. (1991). Ensaios sobre Heidegger e outros. Instituto Piaget.

Polster, E. \& Polster, M. (2001). Gestalt-terapia integrada. Summus.

Rorty, R. (1994). A filosofia e o espelho da natureza. Relume-Dumará

Santos, B. S. (2010). Um discurso sobre as ciências. Cortez.

Stein, E. (1997). A caminho de uma fundamentação pós-metafísica. Edipucrs. 